\title{
Immunopathology and clinical manifestations of severe malaria with special references to Plasmodium falciparum
}

\author{
Supargiyono
}

\begin{abstract}
Abstrak
Gambaran klinis infeksi malaria falciparum bervariasi mulai dari tanpa gejala sampai ke manifestasi berat seperti gagal ginjal, edema paru dan malaria otak. Namun demikian proses-proses imunopatologis yang mendasari berbagai manifestasi klinis tersebut masih belum jelas. Makalah ini merupakan kilas balik (review) terhadap berbagai hasil penelitian imunologi dan patologi infeksi malaria baik pada manusia maupun pada binatang, dengan tujuan untuk memperluas wawasan dan pengetahuan tentang mekanisme imunopatologis yang melatarbelakangi terjadinya berbagai manifestasi klinis pada infeksi malaria.
\end{abstract}

\begin{abstract}
The clinical pictures of falciparum malaria varies from asymptomatic to severe manifestation such as acute renal failure, pul monary oedema and cerebral malaria. However, the immunopathological mechanisms which underlies those clinical manifestations still not clear. This paper reviewed some such studies both in human and animal model of the diseases, with the aim to broadened the understanding of the immunopathology of human malaria infection. With a deep understanding on the immunopathological mechanisms which underlies any clinical manifestation during malaria infection the useful theurapetic interventions can be designed.
\end{abstract}

Keywords: plasmodium falciparum, cerebral malaria, immunopathology, severe manifestation, cytoadherent

\section{INTRODUCTION}

Malaria remains a widespread disease and represent a major public health problem in much of tropical countries in the world. It has been calculated that more than $45 \%$ of the world population are exposed to malarious areas, and as many as 500 million clinical cases have been reported each year. ${ }^{1}$ About half of malaria cases are caused by infection with Plasmodium falciparum which constitute the main cause of death of malaria especially in children under the age of five. The clinical manifestation of malaria infections varies from asymptomatic or influenza like clinical picture to severe complicated manifestation such as renal failure, pulmonary oedema and cerebral malaria. Studies on the immunological reaction as well as histopathological changes occured during malaria infections have been broadly documented both in human and in animal model of the diseases. This article reviewed some such studies, with the aims to achieve a broader understanding in the immunopathological mechanisms which may underlies the variety of clinical manifestations of malaria infections.

Department of Parasitology, Faculty of Medicine, Gadjah Mada University, Yogyakarta, Indonesia

\section{THE CLINICAL PICTURES OF MALARIA INFECTION}

Within their cycle of development, malarial infections are initiated by the injection of sporozoites through the bite of an infected mosquito, followed by intrahepatic/exoerythrocytic development before entering the erythrocytic cycle. When someone never exposed to malaria becomes infected, they usually remain healthy until the parasite develops and begins to build up in numbers. Prodromal symptoms may develop when the numbers of infected red cells are still very low and difficult to detect on the blood smears. The clinical picture then varies, and may range in severity from a mild headache to serious illness such as pulmonary oedema. However, the majority of infections develop in a well-recognized pattern, e.e. fever alternating with asymptomatic periods. The duration of prepatent and incubation periods is influenced by the species of the parasite, the degree of innate and acquired immunity, and probably the number of sporozoites injected. The rise in temperature corresponds to the rupture of infected erythrocytes. When the development of asexual blood stage parasites is largely synchronous, the periodicities of fever, which are determined by the length of the asexual cycle, are distinct; every $48 \mathrm{~h}$ in $P$. vivax, $P$. falciparum and $P$. ovale (tertian malaria), every 36 
h in some strains of $P$. falciparum (subtertian malaria) or every $72 \mathrm{~h}$ in $P$. malariae (quartan malaria). However, sometimes the asexual erythrocytic development is not synchronous, and two or more broods develop, so that schizogony occurs each day, giving rise to daily or quotidian paroxysms. The features of the paroxysm comprises three stages: 1). Cold stage: extremely cold, violent shivering and dry skin, this stage lasts for 15-60 minutes. 2). Host stage: a feeling of intense heat, the skin hot and dry, pulse and respiration rates increased, and the temperature possibly reaching $40^{\circ} \mathrm{C}$ or even higher. The patient may complain of severe retroorbital headache, extreme thrist and restlessness, and delirium frequently occurs. The hot stage may persist for up to 2 hours. 3). Sweating stage: the patient suddenly bursts into profuse perspiration, initially on the temples but rapidly becoming generalized and copious. A feeling of great relief comes over him or her, and all symptoms disappear, the temperature falls, the patient feels extremely tired and usually falls asleep. When he wakes; he feels well and prepared to do his daily routine.

Infection with $P$. falciparum is the most serious form of malaria, and therefore will be considered in greater detail. The clinical pictures and the outcomes of the disease vary greatly. They may be uncomplicated, or associated with serious or even fatal complications.

\section{Falciparum malaria with uncomplicated manifes- tations}

Immunity acquired by prior infection or inadequate use of suppressive drugs may modify the onset of illness. In such cases, parasites may exist in the blood for some time before clinical manifestations develop, and the onset of illness is insidious with non-specific symptoms such as malaise, backache, diarrhoea and persistent dyspepsia. The pattern of fever seems to be influenced by the immune status of the host, and the synchronicity of asexual erythrocytic development. The fever is usually irregular at first, and shows no sign of periodicity. The paroxysms are often not regular and temperature peaks sometimes establish subtertian or even quotidian forms. The spleen enlarges rapidly, and is usually palpable within a week of the onset of infection. Some degree of jaundice and elevation of serum bilirubin may be observed, especially in heavy infections. Anaemia is a common feature of falciparum malaria. However, in mild cases, there may be little or no obvious anaemia. In severe infections, loss of red cells may be rapid, accompanied by black water fever (dark urine). In $P$. falciparum infection, the latter stages of asexual erythrocytic development takes place in deep vasculatures (sequestered), so that normally only young trophozoites (ring forms) appear in the peripheral blood. In heavy infections, however, all forms of erythrocytic stages are present, with a domination of ring forms. Gametocytaemia usually occurs in the second week after the onset of parasitaema, and may persist for some time after cure. If the acute attack is adequately treated, and no pernicious symptoms develop, there is usually no risk to life. Recrudescence may occur around 9-12 months after the primary attack.

\section{Falciparum malaria with pernicious manifesta- tions and complications}

A pernicious manifestation in $P$. falciparum infection is common in poorly immune individuals, and to be expected if the parasitaemia is more than $5 \%$, if more than $10 \%$ of infected red cells contain multiple infection, or if many schizonts are present in the circulation. In an area where falciparum malaria is holo- or hypeendemic, most severe manifestation occurs in young children over the age of 6 months, and is less common in adults, due to acquisition of partial immunity. This immunity may lapse in pregnant women, in those who have lived away from the endemic area for several years, or as result of immunosuppresive treatment. Travellers, migrant workers, and transmigrants from non-malarious areas, are also vulnerable to severe infection.

The definition of severe infection in falciparum malaria as outlined by WHO is essential for clinicians and health workers to determine which management should be taken, so that the mortality can be reduced. This definition describes the criteria for severe manifestations, which includes: cerebral malaria, severe anaemia, renal failure, pulmonary oedema or adult respiratory distress syndrome, hypoglycaemia, circulatory collapse/shock and haemoglobinuria. $\mathrm{Ob}$ servation of one or more of these features in the presence of asexual parasitaemia implies severe falciparum malaria. ${ }^{1}$ In this review, discussion will be concentrated particularly on severe anaemia, cerebral malaria and renal failure, the three gravest and most common severe manifestations of falciparum malaria.

\section{Severe anaemia}

Severe anaemia is defined as a normocytic anaemia with haematocrit $<15 \%$ or haemoglobin $<5 \mathrm{~g} / \mathrm{dl}$, with parasitaemia more than $10,000 / \mathrm{ml}$. The actual cause of the anaemia that occurs during malarial infection is 
difficult to define. These difficulties are compounded by infection is difficult to define. These difficulties are compounded by many other factors, such as the rapidity at which high parasitaemias are reached in non- immune persons, and the variability of clinical features with respect to the immun status of the patient. In certain areas, patients frequently exhibit multiple pathology, including iron and folate deficiency, bacterial or other parasitic infections, and genetic disorders of the red cells. Furthermore, the effect of malarial infection involves many organ systems which may contribute to the development of a naemia.

In general, anaemia occurs if there is a defect in red cell production, or if there is an increased rate of loss either by haemolysis or bleeding. Defective production may result from either inappropriate proliferation of red cell precursors, or destruction during maturation in the bone marrow, i.e. ineffective erythropoiesis. It is likely that both haemolysis and defective proliferation and maturation occur simultaneously during human malarial infection.

\section{Haemolysis}

During intra-erythrocytic development, infected erythrocytes rupture at the end of each cycle. This constitutes a major factor in producing anaemia. Some features of haemolytic processes, such as hyperbilirubinaemia, haemoglobinuria and a dramatic fall of haemoglobin levels, are usually observed. The destruction of red cells seems to occur both intravascularly and by sequestration of parasitized red cells in the spleen and in the micro circulation of other organs. Premature red cell lysis probably occurs due to impaired membrane function or increased rigidity leading to reduced deformability. The spleen is a highly effective filter for damaged or rigid cells. Immune-mediated haemolysis has also been suggested as the mechanism causing anaemia among children in holo-endemic malaria areas of West Africa. Red cells coated with $\mathrm{IgG}$ are more rapidly removed from the circulation by the spleen in patients with acute falciparum malaria. The increase in numbers and activation of splenic mononuclear phagocytes, including increases in Fcreceptor expression, probably play an important part in this phenomenon.

There is considerable evidence from animal experiments that non-parasitized red cells also have shortened survival during malarial infections, since the haemoglobin level continues to fall for periods of up to several weeks after the parasite has been cleared from the circulation. Increased rates of erythrocyte destruction following clearance of the parasites was also observed in patients during $P$. falciparum and $P$. vivax infections. ${ }^{2}$ However, the mechanism is unclear.

\section{Defective red cell production}

Many workers have noted that there is a relatively poor reticulocyte response in patients with $P$. falciparum malaria. However, ineffective erythropoiesis during malaria infections may also be the result of other factors such as iron and/or folic acid deficiency. Dyserythropoiesis has also been demonstrated in the bone marrow of patients during acute $P$. falciparum infections. ${ }^{2}$ Light and electron microscopic studies of marrow aspirates from $P$. vivax infected Thai adults also demonstrate evidence of dyserythropoiesis as well as ineffective erythropoiesis, without any picure of micro-vascular obstruction by infected red blood cells. ${ }^{2}$ Similar studies carried out on Thai patients with complicated $P$. falciparum infection showed that the majority of erythrocytes within bone marrow sinusoid were parasitized, and that these cells were attached to endothelium. Some sinusoids were packed and even completely blocked by parasitized cells. The appearance of reticulocytes in the peripheral blood was delayed, but the myeloid to erythroid ratio did not change significantly.

The mechanism which is responsible for dyserythropoietic changes observed during human malaria infections is still unclear. Interestingly, such changes usually occur in young children, with relatively low parasitaemias, without a history of a recent acute illness. Cytokines, notably tumour necrosis factor (TNF), have been shown to mediate many pathological changes during malarial infection, including depressing erythropoiesis, and contributing to dyserythropoiesis, ${ }^{2}$ in murine malarial models. This cytokine probably also contribute to dyserythropoiesis in human falciparum infection. In this respect, it is relevant to refer to the role of resident bone marrow macrophages in the modulation of erythropoiesis during experimental malarial infections. These cells are in close association with bone marrow haemopoietic progenitors, and are capable of releasing cytokines including TNF and haemopoietic growth factors. ${ }^{3}$ An increase in the numbers of myeloid progenitors within bone marrow haemopoietic clusters ${ }^{4}$ probably also occurs during human infection, and in turn, contributes to the decrease of erythropoiesis presumably through a competitive haemopoietic progenitor development. 
Other factors, such as tropical splenomegaly syndrome, G6PD deficiency and the administration of anti-malarial drugs, may also potentiate the development of anaemia during malarial infection. Haemoglobinuria, which is sometimes observed during long term treatment with quinine, has been thought to be due to sensitisation of the red cells. However, evidence of quinine-mediated haemolysis has not been demonstrated.

\section{Cerebral malaria}

Cerebral malaria is defined as an unrousable coma not attributable to any other cause in a patient with falciparum malaria. The coma, which is determined as failure to localise or make an appropriate verbal response to a noxious stimulus, ${ }^{1}$ should persist or at least $\mathbf{3 0}$ minutes after a generalized convulsion.

During human $P$. falciparum infection, erythrocytes containing late asexual blood stage parasites do not circulate, but are selectively sequestered in deep vasculatures. This erythrocyte sequestration tends to generate obstruction of small capillaries, and may result in tissue anoxia. This phenomenon appears to be an essential pathological feature of severe falciparum manifestations, including cerebral malaria.

Erythrocyte sequestration is greatest in the cerebral micro-vasculature of patients with severe falciparum malaria, ${ }^{5}$ and may explain why coma is a prominent feature of cerebral complications in humans. However, the exact mechanism which leads to cerebral abnormalities is still not absolutely clear, and therefore, any pathophysiological changes observed which may underlie cerebral malaria must also be considered. Studies aimed at understanding the pathophysiology of cerebral malaria have been hampered by the fact that so far there is no animal model which can satisfactorily reproduce either the clinical or the pathological features of cerebral malaria in man. For example, cerebral manifestations observed in $P$. berghei ANKA infected mice are obviously due to different mechanisms, while $P$. falciparum infected erythrocytes in Aotus monkeys do not sequestered in cerebral microvessels.

Many hypotheses have been proposed to explain the possible mechanisms causing cerebral malaria, and some are of doubtful relevance to the human disease. These include the "sludging" hypothesis, an initial theory which was based on pathological observations in fatal cases of falciparum malarias: cerebral capillaries contained a high proportion of infected cells even when the parasitaemia was low. It was suggested that infected red cells were stuck together and had difficulty in passing through the capillary beds, therefore, blood flow was reduced and finally stopped.

The "permeability" hypothesis was also proposed, which suggests that increased cerebral capillary permeability, resulted in outward plasma leakage, cerebral oedema, local haemoconcentration and reduced microcirculatory blood flow. The release of plasma kinins was thought to be a possible factor. Some clinical and experimental observations in humans have argued this theory. For example, in the absence of spinal blockage, cerebral oedema which gives rise to increased intracranial pressure must be accompanied by increased lumbar cerebrospinal fluid pressure. Clinical evidence, however, indicated that opening pressures during lumbar punctures are usually normal. In fatal cases, in which the pathological changes should be more severe, the opening pressures were lower than in survivor. Chloroquine, which undoubtedly has an anti-inflammatory activity, has only a small effect on the level of consciousness of falciparum malaria patients. Furthermore, a double-blind placebo-controlled trial of medium and high dose dexamethasone in cerebral malaria patients, did not show any significant effect on patient mortality. ${ }^{6}$ All these observations suggest that cerebral oedema due to increased capillary permeability is probably not the cause of coma in these patients.

Another hypothesis proposed to explain the pathophysiology of cerebral malaria was based on the obstruction of cerebral microvasculatures by infected red cells. This theory suggested that cerebral microvessels are mechanically obstructed by red cells containing mature blood stage parasites, leading to tissue ischaemia and anoxia. Two mechanisms have been proposed which may initiate such obstruction. First, decreased erythrocyte deformability resulting in decreased capacity of these cells to transverse small capillaries and possibly leading to capillary obstruction. Reduction of $P$. falciparum infected red cell deformability has also been demonstrated, which is proportional to the maturation stage of the intracellular parasite. However, this rheological explanation of sequestration has been considered inadequate, because if the obstruction was a result of cell rigidity, the proportion of infected and uninfected cells at the site of obstruction should be similar to that in the blood circulation, and such obstructions should occur wherever capillaries have appropriate internal diameters. This is in contrast to observations of the preferential sequestration of $P$. falciparum infected cells. 
The inadequacy of the deformability theory has led to the suggestion of a second possible mechanism: that there is a specific molecular interaction between infected erythrocytes and the vascular endothelial membrane which mediates cytoadherence. Post-capillary venules are the first site of mature parasite- containing red cells adherence since the shear forces at the vessel wall drop markedly. Uninfected red cells then also bind to the surface of adherent infected cells to form rosetting. This sequence of events has been thought to occur during severe $P$. falciparum infection, leading to microvascular obstruction.

Malaria-infected erythrocy tes undergo changes in their surface antigenic structure during intra cellular parasite development, and some of the molecules involved have been shown to play a part in cytoadherence, while other molecules probably play an important role in antigenic variation. ${ }^{7}$ Electro-dense sub- membranous structures termed as "knobs" have also been suggested to play a role in cytoadherence. These structures contain histidine-rich protein, which are parasite-derived and are exported to the erythrocyte membrane. Initially only knob+ parasite lines are shown capable of cytoadherence, however, knowcytoadhering lines have also been reported. ${ }^{8}$ There are several malarial proteins associated with knobs of $P$. falciparum. These include Pf EMP-1 (EMP: erythrocyte membrane protein), Pf EMP-2 and Pf HRP-1 (HRP: histidine-rich protein). Malarial protein Pf HRP-2 has also been shown to be secreted from intact infected erythrocytes into culture medium. Immunohisto-chemistry studies on the brain tissue of patients using monoclonal antibodies specific for HRP-1 and HRP-2 indicated that these molecules may participate in the attachment of infected red cells to the vascular endothelium, causing microvascular obstruction. ${ }^{9}$ Since cytoadherence can also be inhibited by strain-specific antisera, ${ }^{10}$ these molecules are probably also capable of mediating antigenic variation, a wellknown mechanism of immune evasion.

For the adhesion to occur, there must be another molecule on the surface of the endothelium which would act as a receptor. Several in vitro studies indicated that $P$. falciparum infected erythrocytes adhere on cultured human umbilical vein endothelia, mononuclear phagocytes, and the amelanotic melanoma cell line $\mathrm{C} 32$, via the same receptor. A monoclonal antibody OKM5, which has been shown to react with most capillary and venule endothelium, was subsequently found to inhibit cytoadherence of $P$. falciparum infected erythrocytes to endothelium. ${ }^{11}$
A glycoprotein of $\mathrm{M}_{\mathbf{r}} 88,000$ (CD36 or GP88) is the obvious target of the OKM5 antibody. CD36 or GP88 has a wide range of distribution including mononuclear phagocytes, capillary endothelium, platelets and some tumour cell lines such as C32. ${ }^{11}$ The normal function of CD36 antigen is still not clear. However, induction of this antigen expression on U937 cells and on simian melanoma cell lines has been shown to correlate with increased ability of these cells to act as the target for cytoadherence of $P$. falciparum infected erythrocytes. ${ }^{12}$ CD36 has also been shown to bind directly to infected erythrocytes, and has been demonstrated on the brain vascular endothelium of patients with or without cerebral malaria. ${ }^{11}$

Another molecule which may act as receptor for infected erythrocytes is thrombospondin, ${ }^{13}$ a glycoprotein which is synthesized by many adherent cells including endothelium, and plays a role in cell-to-cell or cell-to-matrix interaction. Thrombospondin has also been suggested to act as a receptor which mediates the adhesion of $P$. falciparum infected erythrocytes to microvessel endothelium of the rat mesocoecum in the exvivo model. ${ }^{14}$ Studies with COS cell transfectants and human umbilical vein endothelium have identified intercellular adhesion molecule-1 (ICAM-1) as the receptor which mediates binding of infected erythrocytes to these cells. ${ }^{15}$ Other molecules, such as endothelial leucocyte adbesion molecule-1 (ELAM-1) or E-Selectine, and vascular cell adhesion molecule-1 (VCAM-1) have also been suggested to act as endothelial receptors for infected erythrocytes. ${ }^{12}$ It seems likely that the diversity in cytoadherence receptor expression on vascular endothelium will bring about diversity of red cell sequestration properties, and in turn might contribute to the variety of clinical manifestations of the diseases. This probably also explains why in a certain area $\boldsymbol{P}$. falciparum causes severe manifestation in some children but not all.

At autopsy, the microvasculature of patient who have died from severe malaria is usually congested and blocked with infected and uninfected red cells. ${ }^{16}$ The sequestration of red blood cells during $P$. falciparum infection is now believed to reflect binding of infected erythrocytes to vascular endothelium (cytoadherence), as well as adhesion of non-infected to infected erythrocytes (rosetting). The relative importance of rosetting versus endothelial binding in inducing cerebral pathology is still not known. Studies in the Gambia have demonstrated that all isolates from cerebral malaria patients formed rosettes, and that the mean rate of rosette formation in isolates from cerebral 
malaria children was twice as high as that in isolates from uncomplicated malaria. Furthermore, patients with uncomplicated malaria had high levels of antirosette antibody in the serum, while patients with cerebral malaria did not. ${ }^{17}$ When parasitized red blood cells from patients with cerebral and uncomplicated malaria were tested for their ability to bind melanoma cells, no differences were observed. ${ }^{17}$ These observations indicate a strong association between rosette formation of $P$. falciparum infected erythrocytes and cerebral malaria. More recently, it has also been reported that rosette formation of $P$. falciparum infected erythrocyte can be mediated by several molecular mechanisms involving parasite polypeptides with molecular weights of 22,000 or 28,000 , termed rosettins. ${ }^{18}$ Antibodies to both polypeptides disrupt rosettes in a strain specific fashion. Polyclonal anti-22,000- $\mathrm{M}_{\mathrm{r}}$ rosettin antibodies raised in mice or rabbits strongly stain the surface of nonfixed erythrocytes infected with late asexual stages of rosetting $P$. falciparum. The $22,000-\mathrm{M}_{\mathrm{r}}$ rosettin is accessible for surface iodination on erythrocytes infected with strains of rosetting parasites sensitive to anti$22,000-\mathrm{M}_{\mathrm{r}}$ rosettin antibodies, but no labelling was observed on either normal erythrocytes or non-rosetting $P$. falciparum infected erythrocytes. Purified anti$22,000-\mathrm{M}_{\mathrm{r}}$ rosettin serum IgG was also shown to precipitate three parasite-derived polypeptides with molecular weights of $22,000,45,000$ and 50,000 from lysates of $\left({ }^{35} \mathrm{~S}\right)$ methionine-labelled $P$. falciparum-infected erythrocytes. ${ }^{18}$ These observations suggest that rosetting is mediated by strain specific, antigenically distinct parasite-derived polypeptides.

Immune mechanisms of the host are other factors which should also be considered to play a role in the pathogenesis of cerebral malaria. This has been clearly demonstrated in experimental malaria models. However, evidence for the role of the immune mechanism in the pathogenesis of human cerebral malaria is still very poor. Malarial infections induce both humoral and cell- mediated immune responses, and complement activation is prominent during human falciparum infections. Attempts to demonstrate immune complex deposition along the vascular endothelium which may lead to immune complex vasculitis in the brain patients with cerebral malaria have resulted in different findings. Aikawa et al, ${ }^{19}$ were able to demonstrate linear staining of $\operatorname{IgG}, \operatorname{IgM}$ and $P$. falciparum antigen Pf.HRP-1 along the walls of cerebral vasculature, which were negative in the normal human brain controls. In contrast, other study could not demonstrate the presence of immunoglobulins and $P$. falciparum an- tigens. These differences are probably also result from differences in treatment, the stages of the disease, and immunohistochemical techniques used.

\section{Acute renal failure}

Renal disease in association with quartan and falciparum malaria has been well documented. ${ }^{5}$ Acute renal failure is an important complication of severe falciparum malaria, with predisposing factors of heavy parasitaemia and/or acute intravascular haemolysis. Renal failure is defined as urine output $<400 \mathrm{ml} / 24 \mathrm{~h}$ in adult or $<12 \mathrm{ml} / \mathrm{kg} / 24 \mathrm{~h}$ in children, failing to improve after rehydration and serum creatinine $>3 \mathrm{mg} / \mathrm{dl}$. The essential lesion is renal ischaemia, which is thought to be due to a combination of vasoconstriction mediated by inflammatory cytokines, and adherence of parasitized erythrocytes to vascular endothelium leading to impairment of the renal micro circulation and to renal failure. Cytoadherence of parasitized erythrocytes in the glomerular capillaries is occasionally seen, but not as pronounced as in other organs such as in the brain. Oligouria is the cardinal symptom, and if untreated, may rapidly progress to anuria. Uraemia usually develops gradually, characterized by progressive development of anorexia, nausea, vomiting, nervous irritability, confusion, disorientation, heightened reflexes, seizures, myoclonic muscle-twitching and coma. In patients with acute renal failure, infections of the respiratory and/or urinary tract are common complications, which may lead to septicaemia. Damaged kidneys can no longer eliminate nitrogenous metabolic waste, and this results in retention of inorganic acids which leads to metabolic acidosis. Acidosis is frequently accompanied by pulmonary oedema, shock and hypoglycaemia. High plasma lactate levels and decreased arterial blood $\mathrm{pH}$ are indicative of acidosis. Studies on patients with cerebral malaria from Thailand showed a mild proteinuria, and their urinary sediment lacked red cells casts, the hallmark of glomerulonephritis. 1

In a view of the intense malarial antigenaemia during severe $P$. falciparum infection, it can also be speculated that the kidney should demonstrate some degree of histopathological changes due to immune complex deposition. Immuno-histochemical studies of kidneys from monkeys during $P$. falciparum infection show a mesangiopathic glomerulonephropathy with some deposition of $\mathrm{IgG}, \mathrm{IgM}$ and $P$. falciparum antigens in the mesangium. ${ }^{5}$ Meanwhile, Iseki et al ${ }^{19}$ studied the renal pathology in monkeys during vaccine trials with a recombinant protein of the ring-infected erythrocyte 
surface antigen (RESA) of $P$. falciparum. Deposition of $\mathrm{IgG}, \mathrm{C} 3$ and $P$. falciparum antigens in the mesangium was also observed, accompanied by mesangiopathic glomerulonephropathy, but a relationship between the severity of parasitaemia at the time of death and the presence of nephropathy was not apparent. A similar study was carried out in squirrel monkeys during vaccine trials using four recombinant circumsporozoite (CS) proteins, rPvCS-1; rPvCS-2; rPvCS-3 and NS1 sub(81) V sub(20) of $P$. vivax. The monkeys were immunized, then challenged with $P$. vivax sporozoites. Among 33 post-trial biopsies, 17 has mild to moderate mesangial proliferation and 9 had interstitial nephritis. Deposition of $\mathrm{IgG}$ was found in only 3 of 24 specimens, and deposition of $\mathrm{C} 3$ and malarial antigens in the glomeruli was not found. There was no correlation between the severity of nephropathy and the intensity of parasitaemia. However, the immunopathological changes that occur during human falciparum infection still need to be clarified.

\section{The role of cytokines on the pathology of malaria}

Cytokines are proteins/glycoproteins with relatively low molecular weights, produced by a variety of cells and capable of acting on nearly every tissue and organ system. During inflammation and infection, such as during bacterial or parasitic infections, the genes for most of the cytokines are expressed. ${ }^{20}$ Some cytokines may have host protective effects whereas others may contribute to the development of immunopathology or even to the death of the host. Apart from their beneficial effects to the host, cytokines released during malarial infections have been shown to contribute to pathology.

IFN- $\gamma$, TNF- $\alpha$ and IL- 1 are among other cytokines released during experimental malarial infections, which may be involved in the development of pathology. IFN- $\gamma$ may induce the gene expression of TNF- $\alpha$ and IL-1 in macrophages, while TNF and IL-1, which are also named as pro-inflammatory cytokines, may induce the secretion of other cytokines and inflammation. Independent experiments indicate that both TNF and IL-1 possess similar properties such as the induction of fever and shock syndromes, elicitation of hepatic acute phase proteins, and the activation of lymphocytes. ${ }^{21}$

Monocytes from Gambian patients with acute malaria also demonstrated a higher capacity to release TNF than monocytes from normal or convalescent in- dividuals. ${ }^{2} P$. falciparum antigens have also been shown to induce the secretion of TNF by human blood monocytes ${ }^{21}$ and erythrocyte cultures of $P$. falciparum to induce secretion of TNF by human mononuclear cells with the highest levels soon after schizont rupture. $^{22}$ Injection of TNF into cancer patients also resulted in fever in all recipients, and in many of them this was also accompanied by chill, rigor, headache and anorexia. ${ }^{23}$ It is most likely that TNF is at least partly responsible for the fever that follows schizogony in patients with malaria. TNF has also been shown to induce hypoglycaemia, hypotension, dyserythropoiesis and erythrophagocytosis in experimental animals. Dyserythropoiesis and erythrophagosytosis observed in $P$. falciparum patients is probably also due to TNF. There is also a positive correlation between TNF levels in the serum and the severity of the disease. Among Gambian children infected with falciparum malaria, the serum levels of TNF were highest in patients that later died of cerebral malaria, moderate in those did not die, and lowest in uncomplicated malaria. ${ }^{23}$ TNF has also been shown to increase the adhesive properties of endothelial cells and leucocytes, ${ }^{23}$ probably through the induction of surface adhesion molecule expression. It is also possible that circulating or locally generated TNF may accelerate the cytoadherence of infected erythrocytes to the cerebral vascular endothelium that results in sequestration. TNF may also contribute to the development of neurological manifestations of cerebral malaria through induction of NO release. Since TNF is becoming increasingly important in many of the pathological changes during malarial infections, this cytokine is now being considered as a target for a new strategy malarial vaccine development: anti-disease vaccine.

\section{CONCLUSIONS}

The recent accumulation of information on the properties, and distribution, of parasite- and host-derived polypeptides associated with cytoadherence of infected erythrocytes, has broadened the horizons of our understanding of the pathophysiology of malarial infections. It is becoming obvious that erythrocyte sequestration, which can be attributed to the attachment of infected erythrocytes onto microvascular endothelium and the binding of non-infected cells to the attached infected cells (rosette formation), is a major factor contributing to the development of severe disease manifestations in human falciparum infections. Although the evidence is still indirect, cytokines, including TNF, are likely to play a part in this process. Within the network of interaction between these 
molecules lie many opportunities for rational therapeutic intervention. For example, specific antibodies against parasite antigen or its receptors on endothelium can be produced, and could be used for dispersing or preventing cytoadherence. In any case, the relative importance of different endothelial receptors, cytoadherence, rosette formations, and cytokines, in the pathology of severe falciparum malaria, still need to be elucidated. It is from such studies that the most useful therapeutic measures are likely to emerge.

\section{REFERENCES}

1. WarrelI DA, Molyneux ME, Beales PF. Severe and complicated malaria. Trans R Soc Trop Med Hyg, 1990, 84 (Supplement 2):1- 65.

2. Hamada A, Watanabe N, Tanaka H, Kobayashi A. Falciparum malaria with bone marrow abnormality resembling malignant histiocytosis. Trans R Soc Trop Med Hyg, 1989,83:331.

3. Supargiyono. Imunitas seluler pada malaria: 5. Perubahan kadar pengatur mielomonositopoetik pada mencit yang diimunisasi dan tidak diimunisasi selama infeksi Plasmodium vinckei petteri. Maj Ked Indon 1997,47: No.11:55562.

4. Supargiyono. Cell mediated immunity in malaria: 2. Changes in proliferation activities of mononuclear phagocyte progenitors during Plasmodium vinckei petteri infection in immunized and non- immunized mice. Maj Kedok Indon 1994,44:384-92.

5. Aikawa M, Iseki M, Barnwell JW, Taylor D, Oo MM, Howard RJ. The pathology of human cerebral malaria. Am J Trop Med Hyg, 1990,43(Suppl):30-7.

6. Hoffman SL, Rustama D, Punjabi NH, Surampeat B, Sanjaya B, Dimpudus AJ, McKee KT, Paleologo FP, Campbell JR, Marwoto H, Laughlin L. High-dose dexamethasone in quinine-treated patients with cerebral malaria: a doubleblind, placeo-controlled trial J Infect Dis, 1988,158:325-31.

7. Hommel M. Cytoadherence of malaria-infected erythrocytes. Blood Cells 1990,16:605-19.

8. Udomsangpetch R, Aikawa M, Berzins K, Wahlgren -M, Perlmann P. Cytoadherence of knobless Plasmodium falciparum-infected erythrocytes and its inhibition by human monoclonal antibody. Nature, 1989,338:763-5.

9. Igarashi I, Oo MM, Stanley H, Reese R, Aikawa M. Knob antigen deposition in cerebral malaria. Am J Trop Med Hyg, 1987,37:511-5

10. Singh B, Ho M, Looareesuwan S, Mathai E, Warrell DA, Hommel M. Plasmodium falciparum : inhibition/reversal of cytoadherence of Thai isolates to melanoma cells by local immune sera. Clin Exp Immunol, 1988,72:145-50.

11. Barnwell JW, Asch AS, Nachman RL, Yamaya M, Aikawa M, Ingravallo P. A human 88-kD membrane glycoprotein (CD36) function in vitro as a receptor for a cytoadherence ligand on Plasmodium falciparum infected erythrocytes. J Clin Invest, 1989,84:765-72.

12. Ockenhouse CF, Tegoshi T, Maeno Y, Benjamin C, Ho M, Kan KE, Thway Y, Win K, Aikawa M, Lobb RR. Human vascular endothelial cell adhesion receptors for Plasmodium falciparum-infected erythrocytes: roles for endothelial leucocyte adhesion molecule- 1 and vascular cell adhesion molecule-1. J Exp Med, 1992,176:1183- 9.

13. Sherwood JA, Robert DD, Spitalnik SL, Marsh K, Harvey EB, Miller LH, Howard RJ. Studies on the receptors on melanoma cells for Plasmodium falciparum-infecred erythrocytes. Am J Trop Med Hyg, 1989,40:119-27.

14. Rock EP, Roth EF, Rojas-Corona RR, Sherwood JA, Nagel RL, Howard RJ, Kaul DK. Thrombospondin mediates the cytoadherence of Plasmodium falciparum-infected red cells to vascular endothelium in shear flow condition. Blood, 1988,71:71-5.

15. Berendt AR, Simmons DL, Tansey J, Newbold CI, Marsh K. Intracellular adhesion molecule-1 is an endothelial cell adhesion receptor for Plasmodium falciparum. Nature 1989,341:57-9.

16. Riganti M, Pongponratn E, Tegoshi T, Looareesuwan S, Ponpoowong B, Aikawa M. Human cerebral malaria in Thailand: a clinico-pathological correlation. Immunol Letters, 1990,25:199-206.

17. Treutiger CJ, Headland I, Helmby H, Carlson J, Jepson A, Twumasi P, Kwiatkowski D, Greenwood BM, Wahlgren M. Rosette formation in Plasmodium falciparum isolates and anti-rosette activity of sera from Gambian children with cerebral or uncomplicated malaria. Am J Trop Med Hyg, 1992,46:503-10.

18. Helmby H, Cavelier L, Pettersson U, Wahlgren M. Rosetting Plasmodium falciparum-infected erythrocyte express unique strain- specific antigens on their surface. Infection and Immunity, 1993,61:284-8.

19. Iseki M, Broderson JR, Pirl KG, Igarashi I, Collins WE, Aikawa M. Renal pathology in owl monkeys in Plasmodium falciparum vaccine trials. Am J Trop Med Hyg, 1990,43(2):130-8.

20. Dinarello CA. Interleukin-1 and tumour necrosis factor: effector cytokines in autoimmune diseases. Seminars in Immunol, 1992,4:133-45.

21. Titus RG, Sherry B, Cerami A. The involvement of TNF, IL-1 and IL-6 in the response to protozoan parasites. Parasitol Today, 1991,7:A13-6.

22. Kwiatkowski D, Hill A. VS, Sambou I, Twumasi P, Castracane J, Manogue KR, Cerami A, Brewster DR, Greewood BM. TNF concentration in fatal cerebral, nonfatal cerebral, and uncomplicated $P$, falcipanum malaria. Lancet 1990,336:1201-6.

23. Grau GE, Taylor TE, Molyneux ME, Wirima JJ, Vassalli P, Hommel M, Lambert PH. Tumor necrosis factor and disease severity in children with falciparum malaria. New Eng J Med, 1989,320:1586- 91 